\title{
Validação de metodologia para dosagem de porfirinas urinárias por cromatografia líquida de alta eficiência
}

\author{
Atecla Nunciata Lopes Alves ${ }^{1 *}$, Marcelo Nascimento Burattini ${ }^{1}$, Nairo Massakazu Sumita ${ }^{1}$, \\ Henrique Vicente Della Rosa ${ }^{2}$
}

\footnotetext{
${ }^{1}$ Serviço de Bioquímica Clínica, Setor de Toxicologia da Divisão de Laboratório Central do Hospital das Clínicas da Faculdade de Medicina da Universidade de São Paulo / Laboratório de Investigação Médica 03,

${ }^{2}$ Departamento de Análises Clínicas e Toxicológicas, Faculdade de Ciências Farmacêuticas,

Universidade de São Paulo
}

*Correspondência:

A. N. L. Alves

Laboratório Central - HCFMUSP

Av. Dr. Enéas de Carvalho Aguiar,155

Prédio dos Ambulatórios, $2^{\circ}$ andar,

bloco 9

05403-010 - São Paulo - SP, Brasil

E-mail: atecla@terra.com.br
Porfirinas são produtos originados da biossintese do heme. As enzimas envolvidas neste processo podem ter sua atividade inibida por fatores genéticos, adquiridos ou uma combinação de ambos, acarretando um aumento sérico do substrato correspondente que será eliminado pela urina. Considerando-se a importância do diagnóstico precoce nas alterações da biossintese do heme, o objetivo deste trabalho foi desenvolver um método de cromatografia líquida de alta eficiência (CLAE) com detecção por fluorescência, sensivel o suficiente para identificar cinco frações de porfirinas urinárias: uroporfirina (8-carboxil porfirina), heptaporfirina (7-carboxil porfirina), hexaporfirina (6-carboxil porfirina), pentaporfirina (5-carboxil porfirina) e coproporfirina I e III (4- carboxil porfirinas). Métodos de extração por detecção espectrofotométrica não são sensiveis para este propósito. $O$ cromatógrafo utilizado, da marca Shimadzu, é composto de duas bombas, injetor automático e detector de fluorescência (RF-535) com excitação de $400 \mathrm{~nm}$ e emissão de $620 \mathrm{~nm}$. Foi utilizada uma coluna de fase reversa com um programa de gradiente linear. $O$ método desenvolvido apresentou linearidade de 8,0 a 120,0 $\mu \mathrm{g} / \mathrm{L}$ para as frações de interesse, demonstrando ser adequado na identificação e quantificação das porfirinas com diferentes grupos carboxílicos, importantes para o diagnóstico precoce e acompanhamento de porfirias.
Unitermos

- Porfiria

- Porfirinas urinárias/dosagem

- Cromatografia líquida de alta eficiência 


\section{INTRODUÇÃO}

\section{Porfirinas e biossíntese do heme}

Porfirinas são compostos tetrapirrólicos policarboxilados originados no processo de biossíntese do heme (Figura 1). As características estruturais do heme e a presença de um átomo ionizado de ferro o tornam molécula vital para grande variedade de funções biológicas, sendo responsável pelo transporte de oxigênio pela hemoglobina e de elétrons na cadeia respiratória (citocromos a, $\mathrm{a}_{3}, \mathrm{~b}_{1}, \mathrm{c}, \mathrm{e} \mathrm{c}_{1}$ ), pela ativação e decomposição do peróxido de hidrogênio (catalase e peroxidase) e por outras funções de óxido-redução nos citocromos P450 e b $b_{5}$ (Daniell,1997).

A biossíntese do heme ocorre em todas as células humanas, sendo que cerca de $85 \%$ ocorre nas células eritropoéticas da medula óssea, onde todo heme sintetizado é incorporado à hemoglobina, e sua produção é dependente da necessidade de síntese desta (King, Marchesini, 2005). O restante do heme é praticamente sintetizado nos hepatócitos e incorporado às hemoproteínas que compõem o citocromo P450 (Elder, Urquhart, 1987).

\section{Porfirias genéticas e adquiridas}

Porfirias são um grupo de doenças associadas à inibição de enzimas que compõem a rota do heme. As inibições levam ao aumento sérico e à excreção urinária de porfirinas. A Tabela I relaciona o tipo de porfiria, a deficiência enzimática associada, a transmissão genética, a expressão fenotípica e clínica e a classe de porfirina alterada na urina (Doss, Kuhnel, Gross, 2000).

A manifestação de um quadro de porfiria pode estar associada ou ser exacerbada por série de agentes causais, como exposição ambiental e ocupacional a organoclorados (Sunyer et al., 2002) e metais pesados (Hg, Pb e As), alcoolismo, doenças hepáticas e infecciosas, doenças hematológicas e efeito adverso de fármacos (Verdon, Pollock, Bralley, 2006).

A porfiria cutânea tarda (PCT) é o tipo de porfiria mais comumente diagnosticada em humanos, clinicamente caracterizada pela elevada fotossensibilidade e fragilidade cutânea que os indivíduos acometidos por esta moléstia apresentam. Estas manifestações ocorrem às custas da interação das porfirinas com a luz ultravioleta (UV) de 400-410 $\mathrm{nm}$ ao nível da pele (Elder, 1987; Lançoni, 1999). Nestas condições os metabólitos porfirínicos ficam no estado excitado e apresentam fluorescência, podendo neste estado interagir com macromoléculas celulares ou com oxigênio molecular, gerando radicais livres, cito e genotóxicos (Klassen, 1996).

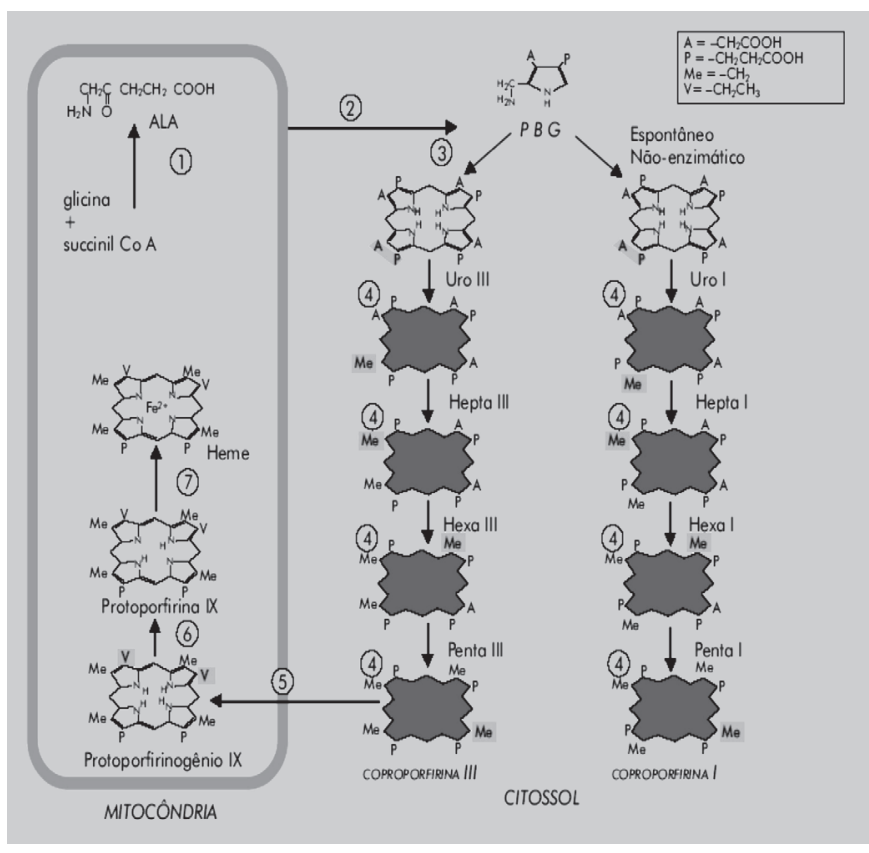

FIGURA 1 - Biossíntese do heme (Verdon, Pollock, Bralley, 2006 modificado)

Enzimas: $\delta$-aminolevulinato (ALA) sintetase, (2) ALA desidratase, (3) uroporfirinogênio I sintetase (PBG desaminase) e uroporfirinogênio III cosintetase, (4) uroporfirinogênio descarboxilase, (5) coproporfirinogênio oxidase, (6) protoporfirinogênio oxidase e (7) ferroquelase (heme sintetase)

Compostos intermediários: ALA: ácido 5- $\delta$-aminolevulínico; PBG: porfobilinogênio; Uro: uroporfirina; Hepta: heptaporfirina; Hexa: hexaporfirina; Penta: pentaporfirina

Os relatos laboratoriais de PCT são caracterizados pelo aumento de uroporfirina (URO) e heptaporfirina (HEPTA) na urina (Ozalla et al., 2002), sendo que a URO está aumentada de 10 a 375 vezes em relação ao valor de referência. Na fase latente da moléstia, quando alterações não são visíveis ao nível da pele, a suspeita clínica pode ser confirmada através das alterações discretas do perfil urinário das porfirinas (Daniell,1997).

Baseados em experiências clínicas e evidências em experimentos com animais, Doss, Kuhnel e Gross (2000) descreveram os estágios da evolução da porfiria hepática crônica, clinicamente latente. As lesões hepáticas subclínicas evoluem progressivamente para o aparecimento das lesões cutâneas. Os estágios iniciais, sem expressão clínica, podem ser identificados no perfil de porfirinas urinárias. No estágio inicial, fase $\mathrm{A}$, aparece uma coproporfirinúria; na fase $\mathrm{B}$, aparece um aumento discreto na fração URO; na $\mathrm{C}$, aparece também o aumento da fração HEPTA e na fase D é desencadeada a PCT (Elder, 
TABELA I - Classificação das principais porfirias (Doss, Kuhnel, Gross, 2000)

\begin{tabular}{|c|c|c|c|c|c|}
\hline Porfiria & $\begin{array}{l}\text { Deficiência } \\
\text { Enzimática }\end{array}$ & $\begin{array}{c}\text { Transmissão } \\
\text { Genética }\end{array}$ & $\begin{array}{l}\text { Expressão } \\
\text { Fenotípica }\end{array}$ & $\begin{array}{l}\text { Expressão } \\
\text { Clínica }\end{array}$ & $\begin{array}{l}\text { Fração } \\
\text { Alterada } \\
\text { (Urina) }\end{array}$ \\
\hline \multicolumn{6}{|c|}{ 1. Eritropoética } \\
\hline CEP & URO III sintase & $\mathrm{AR}$ & Medula óssea & Fotossensibilidade & $\begin{array}{l}\text { URO I e } \\
\text { COPRO I }\end{array}$ \\
\hline EEP & Ferroquelase & $\mathrm{AD}$ & Medula óssea e fígado & Fotossensibilidade & COPRO \\
\hline \multicolumn{6}{|c|}{$\begin{array}{l}\text { 2. Hepática } \\
\text { Agudas }\end{array}$} \\
\hline $\mathrm{ADP}$ & $A L A-D$ & $\mathrm{AR}$ & Fígado & $\begin{array}{c}\text { Visceral e } \\
\text { Neurológica }\end{array}$ & $\begin{array}{c}\text { ALA e } \\
\text { COPRO }\end{array}$ \\
\hline AIP & $P B G$ desaminase & $\mathrm{AD}$ & Fígado & $\begin{array}{c}\text { Visceral e } \\
\text { Neurológica }\end{array}$ & $\begin{array}{c}\text { ALA e PBG } \\
\text { URO e } \\
\text { COPRO }\end{array}$ \\
\hline $\mathrm{HCP}$ & COPRO-O & $\mathrm{AD}$ & Fígado & $\begin{array}{c}\text { Visceral } \\
\text { Neurológica } \\
\text { Fotossensibilidade }\end{array}$ & $\begin{array}{c}\text { ALA, PBG e } \\
\text { COPRO }\end{array}$ \\
\hline VP & PROTO-O & $\mathrm{AD}$ & Fígado & $\begin{array}{c}\text { Visceral } \\
\text { Neurológica } \\
\text { Fotossensibilidade }\end{array}$ & $\begin{array}{c}\text { ALA, PBG e } \\
\text { COPRO }\end{array}$ \\
\hline \multicolumn{6}{|c|}{ Crônicas } \\
\hline PCT & $U R O-D$ & V & Fígado & Fotossensibilidade & $\begin{array}{l}\text { URO e } \\
\text { HEPTA }\end{array}$ \\
\hline HEP & $U R O-D$ & AR & $\begin{array}{c}\text { Fígado e } \\
\text { Medula óssea }\end{array}$ & $\begin{array}{c}\text { Visceral } \\
\text { Neurológica } \\
\text { Fotossensibilidade }\end{array}$ & $\begin{array}{l}\text { URO e } \\
\text { HEPTA }\end{array}$ \\
\hline
\end{tabular}

CEP: porfiria eritropoética congênita; EEP: protoporfiria eritro-thepática; ADP: porfiria por deficiência da ALA-D; AIP: porfiria intermitente aguda; HCP: coproporfiria hereditária; VP: porfiria variegata; PCT: porfiria cutânea tarda; HEP: porfiria hepatoeritropoética; AR: autossômico recessivo; AD: autossômico dominante; V: variável; ALA: ácido 5-deltaaminolevulínico; PBG: porfobilinogênio; URO: uroporfirina; COPRO: coproporfirina

Urquhart, 1987). Esta transição de coproporfirinúria até PCT depende de uma inibição tóxica da atividade da UROD no fígado que pode ou não estar associada, também, a alteração genética pré-existente.

\section{Métodos analíticos para dosagem de porfirinas}

Os métodos utilizados para a dosagem de porfirinas geralmente partem de extração das porfirinas com solvente seletivo, seguida da leitura espectrofotométrica da fração URO e das porfirinas totais. A fração COPRO é obtida pela diferença das porfirinas totais e da fração URO (Fernandez, Henry, Goldenberg, 1966). Métodos fluorimétricos nos quais a separação das duas frações é feita numa coluna com resina de troca iônica também são utilizados (Sobel, Cano, Thiers, 1974; Martinez, Mills,
1971). Para avaliar o perfil urinário de porfirinas visando detectar alterações discretas em fases ainda latentes da doença, estes métodos não são sensíveis (Schreiber, Raysis, Labbe, 1983). Os métodos cromatográficos são, sem dúvida, os de melhor escolha para tal objetivo (Ford, Ou, Ellefson, 1981; Johnson, Perkins, Kennedy, 1988).

\section{MATERIAL E MÉTODO}

\section{Reagentes, padrões e controles e materiais}

Foi utilizado um padrão comercial de porfirinas na forma liofilizada de urina humana, da marca Immundiagnostik (Bensheim, Alemanha KC3601ka), com concentrações conhecidas de URO (8-carboxil porfirina), HEPTA (7-carboxil porfirina), HEXA(6-carboxil porfirina), PENTA(5-carboxil 
porfirina), COPRO I e III (4-carboxil porfirinas): 90,8; 86,8; 88,$8 ; 118,8$ e $187,2 \mu \mathrm{g} / \mathrm{L}$ respectivamente. Este foi ressuspendido com água grau I (NCCLS National Committee for Clinical Laboratory Standards C3-A3, 1997) e acidificado com $25 \mu \mathrm{L}$ de $\mathrm{HCl}$ (37\%) (Néon Comercial Produtos Químicos, São Paulo, SP, Brasil).

Os reagentes utilizados foram acetato de amônio (Synth, São Paulo, SP, Brasil); metanol grau HPLC (EM Science, NJ, USA em associação com Merck KGaA, Darmstadt, Alemanha) e ácido acético glacial. Para a coleta de urina foram utilizados frascos de polipropileno com capacidade para 50 mL (J. Prolab, São José dos Pinhais, PR, Brasil).

\section{Preparo de amostra}

Uma alíquota de 2,0 $\mathrm{mL}$ da amostra foi acidificada com $\mathrm{HCl} 37 \%$ a $\mathrm{pH}<3,0$ e centrifugada a $2.500 \mathrm{rpm}$. O sobrenadante foi submetido a uma unidade filtrante Millex HV 0,45 mm, membrana durapore PVDF, 13 mm diâmetro, não-estéril, Millipore ${ }^{\circledR}$ (Bedford, MA, USA), e diretamente transferido para um frasco de injeção automática de 1,5 mL (Shimadzu Co., Kioto, Japão).

\section{Equipamento e condições cromatográficas}

O cromatógrafo utilizado (Shimadzu Co., Kioto, Japão) é composto de: 1 desgaseificador (DGU-2 A), 2 bombas (LC-10AD), controlador (SCL-10 A), forno de coluna (CTO-10 A), injetor automático (SIL-10A) e detector de fluorescência (RF-535), programado para excitação de $400 \mathrm{~nm}$ e emissão de $620 \mathrm{~nm}$, e um integrador (CR7A PLUS). Foi utilizada uma coluna de fase reversa, $12,5 \mathrm{~cm} \times 14,0 \mathrm{~mm}$, acoplada a uma pré-coluna, $4,0 \mathrm{~cm} \mathrm{x}$ $4,0 \mathrm{~mm}$, ambas $100 \mathrm{RP}-18$ e partícula de $5 \mu \mathrm{m}$, LiChroCART ${ }^{\circledR}$ (Merck KGaA, Darmstadt, Alemanha). O volume de amostra injetado foi de $100 \mu \mathrm{L}$ com vazão de $1,0 \mathrm{~mL} / \mathrm{min}$ e tempo total de análise de 21 minutos. A eluição foi realizada utilizando-se programa de gradiente: metanol e tampão de acetato de amônio $1 \mathrm{~mol} / \mathrm{L}, \mathrm{pH} 4,0$, passando de 10 a $95 \%$ de metanol em 14 minutos e retornando a $10 \%$ em 10 minutos. Este processo teve como objetivo separar as frações das porfirinas às custas das diferenças de polaridade devido ao número de carboxilas.

\section{Validação do método}

A metodologia selecionada foi adaptada do método proposto por Sunyer et al. (2002) e a validação do método foi baseada nos princípios gerais da padronização de um ensaio em métodos cromatográficos (Brasil, Ministério da
Saúde, 2003; Chasin, Chasin, Salvadori, 1994; Shah, Midha, Dighe et al., 1992), que consistem no estabelecimento da linearidade, precisão intra e interensaio, limite de detecção, limite de quantificação e estabilidade da substância na matriz.

O estudo da linearidade foi realizado a partir da diluição da solução de calibrador em seis concentrações diferentes das frações URO, HEPTA, HEXA, PENTA e COPRO. Estas foram submetidas à análise cromatográfica em triplicata. A curva de calibração foi submetida a um tratamento estatístico em que foram calculados o desvio padrão e o coeficiente de variação (CV) de cada ponto. O intervalo dinâmico, isto é, a faixa linear utilizável, foi calculado até a concentração em que o CV para a triplicata era no máximo $10 \%$. As curvas de calibração foram construídas e os coeficientes de correlação de Pearson $\left(\mathrm{r}^{2}\right)$ e as respectivas equações de regressão linear foram estimados.

Baseado no princípio de que o limite de quantificação (LOQ) é a menor concentração precisamente medida e que deve estar incluída na curva de calibração (Brasil, Ministério da Saúde, 2003; Chasin, Chasin, Salvadori, 1994), utilizou-se o critério de reprodutibilidade de resposta (precisão), que consiste em analisar uma série de amostras contendo quantidades decrescentes do analito. O LOQ foi a menor concentração que apresentou um CV que não excedeu o limite de $10 \%$.

O limite de detecção (LOD) é a menor concentração da substância em análise que o processo analítico pode diferenciar, relacionado à linha de base do detector cromatográfico (Brasil, Ministério da Saúde, 2003; Chasin, Chasin, Salvadori, 1994). Baseado neste conceito, o LOD foi calculado pela concentração que equivaleria a uma área de 500 na análise cromatográfica, conforme o programa fixado para esta análise.

A precisão intra-ensaio foi determinada indiretamente pelo cálculo do CV. O estudo foi conduzido analisandose urinas com concentrações conhecidas de URO, HEPTA, HEXA, PENTA e COPRO: 79, 93, 98, 81 e $141 \mathrm{mg} / \mathrm{L}$ respectivamente, com cinco repetições para cada uma. A precisão interensaio foi também estimada pelo cálculo do CV com amostras analisadas em 4 dias diferentes. Foi calculada para as frações URO e COPRO.

A estabilidade dos analitos na matriz foi testada para as frações URO e COPRO para amostra conservada em geladeira $\left(2-8^{\circ} \mathrm{C}\right) \mathrm{em} \mathrm{pH}$ fisiológico de urina $(\mathrm{pH} 5,0-6,0)$ e em pH 9,0, com conservante alcalino. Para as amostras conservadas em freezer (abaixo de $-8{ }^{\circ} \mathrm{C}$ ), foi testada a estabilidade em $\mathrm{pH} 9,0$. Os resultados obtidos ao longo de 7 , $14,21,30$ e 60 dias estão representados em termos de percentual (\%) de perda ou ganho em relação à concentração de URO e COPRO obtida no tempo zero dias. Para as 
amostras conservadas em geladeira, o teste foi realizado por 7 dias.

\section{RESULTADOS E DISCUSSÃO}

Na Figura 2 são apresentados dois perfis cromatográficos: o padrão de porfirinas com as cinco frações que podem ser identificadas. A fração com tR 18,111 representa a mesoporfirina cuja concentração não foi fornecida pelo fabricante. Nesta figura também foi demonstrado o padrão cromatográfico da urina de um indivíduo que não apresentava alterações no perfil de porfirinas urinárias.
O método aplicado demonstrou ser linear dentro da faixa de concentração estudada para as frações das porfirinas. O coeficiente de correlação linear de Pearson $\left(\mathrm{r}^{2}\right)$ apresentou resultados próximos a 0,99 , mostrando a linearidade do método para a faixa de estudo. Na Tabela II estão expostas a faixa de concentração estudada, a correlação e a equação de regressão linear para as respectivas frações estudadas.

Os valores de precisão intra-ensaio, definidos pelo CV dos cinco resultados obtidos para cada fração, estão descritos na Tabela III. Considerando-se que os resultados desejados para precisão, avaliados pelo CV obtido, devem

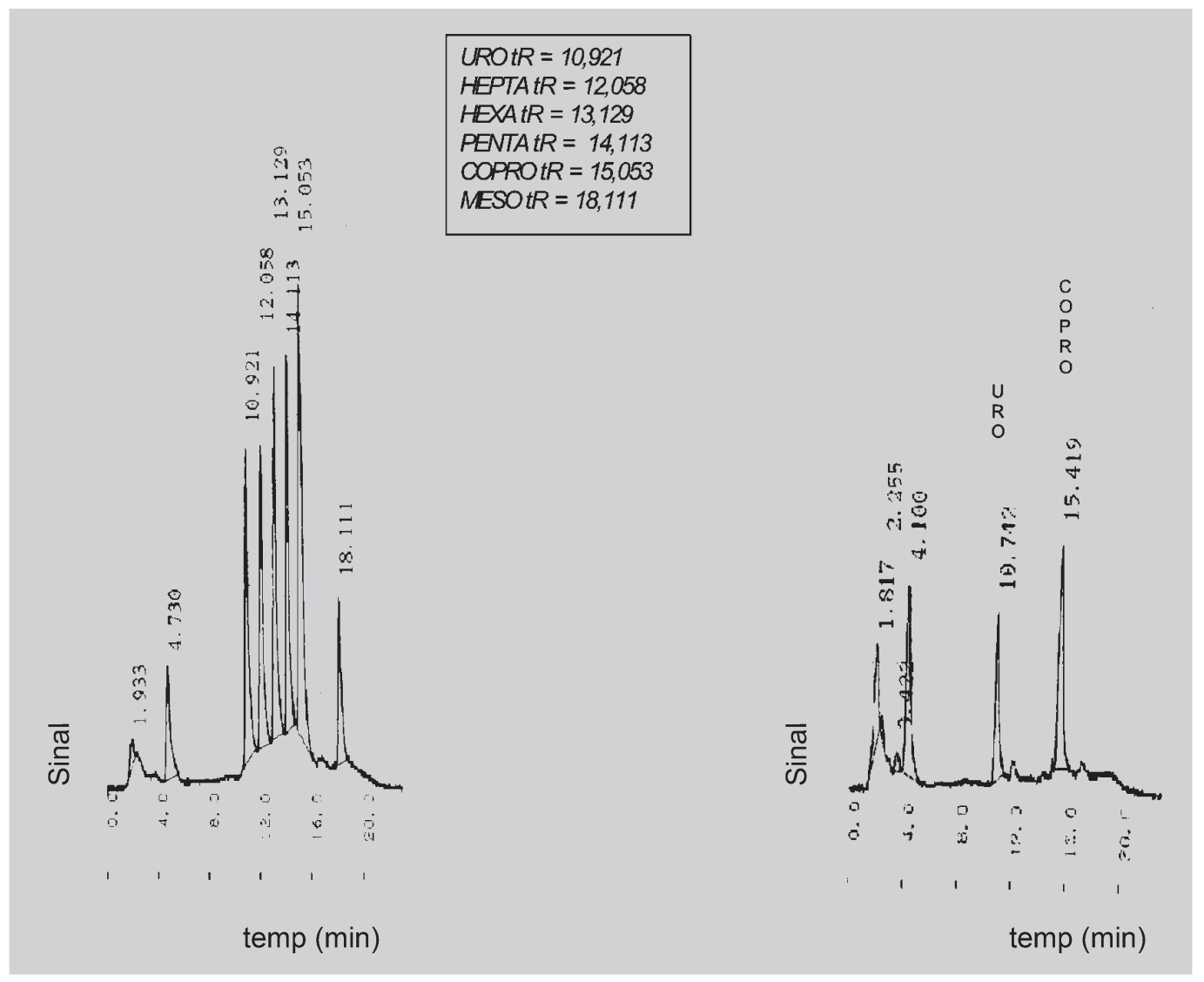

FIGURA 2 - Perfil cromatográfico apresentado pelo padrão utilizado com as 5 frações (esquerda) e amostra de urina sem alteração no perfil de porfirinas (direita).

TABELA II - Correlação e equação de regressão linear obtida para URO, HEPTA, HEXA, PENTA, COPRO na faixa de concentração

\begin{tabular}{lccc}
\hline Fração & Concentração $(\mathrm{mg} / \mathrm{L})$ & Correlação $\left(\mathrm{r}^{2}\right)$ & Equação de Regressão Linear \\
\hline URO & $7,4-90,8$ & 0,9988 & $\mathrm{y}=203,8 \mathrm{x}-676,3$ \\
HEPTA & $6,8-86,9$ & 0,9999 & $\mathrm{y}=192,7 \mathrm{x}-344,9$ \\
HEXA & $8,9-88,8$ & 0,9998 & $\mathrm{y}=168,6 \mathrm{x}-377,0$ \\
PENTA & $8,5-118,8$ & 0,9996 & $\mathrm{y}=157,4 \mathrm{x}-307,8$ \\
COPRO & $8,3-187,2$ & 0,9995 & $\mathrm{y}=119,0 \mathrm{x}+409,9$ \\
\hline
\end{tabular}


TABELA III - Valores de precisão intra-ensaio (CV\%) obtidos com a aplicação do método proposto em amostras de urina adicionadas com URO, HEPTA, HEXA, PENTA e COPRO

\begin{tabular}{lccccc}
\hline \multirow{2}{*}{ Fração } & \multicolumn{5}{c}{ Precisão Intra-Ensaio CV (\%) } \\
\hline Concentração (mg/L) & URO & HEPTA & HEXA & PENTA & COPRO \\
CV (\%) & 79 & 93 & 98 & 81 & 141 \\
\hline
\end{tabular}

ser menores que 15\% (Chasin, Chasin, Salvadori, 1994), os dados obtidos na validação desta metodologia apresentaram precisão adequada, variando de $3,8 \%$ para HEXA até $3,1 \%$ para PENTA na precisão intra-ensaio.

Para a precisão interensaio determinada pelo cálculo do CV com amostras analisadas em 4 dias diferentes para as frações URO e COPRO, os resultados de CV ficaram abaixo de $5,1 \%$ (Tabela IV).

TABELA IV - Valores de precisão interensaio (CV\%) obtidos com a aplicação do método proposto em amostras de urina adicionadas com URO e COPRO

\begin{tabular}{lcc}
\hline & \multicolumn{2}{c}{ Precisão Interensaio CV $(\%)$} \\
FRAÇÃO & URO & COPRO \\
\hline Concentração (mg/L) & 65 & 128 \\
CV (\%) & 5,1 & 2,1 \\
\hline
\end{tabular}

Zuijderhoudt et al. (2000), em estudos de precisão da dosagem de porfirinas por CLAE, encontraram CV menor que $15 \%$ para URO, HEPTA e COPRO. Bozek, Hutta, Hrivnáková (2005) obtiveram CV de 1,9 a 3,1\% para precisão interensaio. Ambos estão de acordo com os resultados obtidos neste trabalho.
Os LOQ apresentados foram calculados de acordo com a repetibilidade da resposta, a menor concentração que não excedeu o $\mathrm{CV}$ de $10 \%$ para cada fração e o LOD pelo conceito relacionado à linha base e área mínima de leitura do detector e integração (Tabela V).

Para o teste de estabilidade, a concentração inicial da fração URO era de $81,1 \mathrm{mg} / \mathrm{L}$ e a fração COPRO de 173,2 $\mu \mathrm{g} / \mathrm{L}$. Tanto para a fração URO como para a COPRO, a amostra conservada em freezer (abaixo de $-8^{\circ} \mathrm{C}$ ) em pH 9,0 apresentou estabilidade por pelo menos 60 dias, com variações obtidas dentro dos limites de precisão do método. Para a amostra conservada em geladeira $\left(2-8^{\circ} \mathrm{C}\right) \mathrm{em} \mathrm{pH}$ $5,0-6,0$ e pH 9,0, a estabilidade testada por 7 dias apresentou uma perda próxima a $10 \%$ para conservação em $\mathrm{pH}$ fisiológico; para o pH 9,0 a amostra mostrou-se mais estável tanto para URO como para COPRO (Tabela VI). Os dados obtidos mostram que a melhor estabilidade foi obtida para conservação em freezer no $\mathrm{pH} 9,0$.

TABELA V - Limites de quantificação e detecção obtidos para as frações de porfirinas urinárias

\begin{tabular}{lccccc}
\hline Fração & URO & HEPTA & HEXA & PENTA COPRO \\
\hline LOQ (mg/L) & 7,4 & 6,8 & 8,9 & 8,5 & 8,3 \\
LOD (mg/L) & 3,3 & 3,4 & 4,0 & 4,8 & 3,6 \\
\hline
\end{tabular}

TABELA VI - Estabilidade da amostra para a fração URO e COPRO conservada abaixo de $-8^{\circ} \mathrm{C}$ e entre $2-8^{\circ} \mathrm{C}$ em $\mathrm{pH}$ $5,0-6,0$ e $\mathrm{pH} 9,0$

\begin{tabular}{|c|c|c|c|c|c|c|}
\hline \multirow[t]{2}{*}{ Tempo (Dias) } & \multicolumn{3}{|c|}{$\begin{array}{l}\text { Diferença de concentração em \% em } \\
\text { relação ao } \mathrm{t}=\mathrm{O} \text {, fração URO }\end{array}$} & \multicolumn{3}{|c|}{$\begin{array}{l}\text { Diferença de concentração em \% em } \\
\text { relação ao } \mathrm{t}=\mathrm{O} \text {, fração COPRO }\end{array}$} \\
\hline & $\begin{array}{c}\text { abaixo de }-8^{\circ} \mathrm{C} \\
\text { pH9,0 }\end{array}$ & $\begin{array}{c}2-8^{\circ} \mathrm{C} \\
\mathrm{pH} 5,0-6,0\end{array}$ & $\begin{array}{l}2-8^{\circ} \mathrm{C} \\
\mathrm{pH} 9\end{array}$ & $\begin{array}{c}\text { abaixo de }-8^{\circ} \mathrm{C} \\
\text { pH9,0 }\end{array}$ & $\begin{array}{c}2-8^{\circ} \mathrm{C} \\
\mathrm{pH}, 0-6,0\end{array}$ & $\begin{array}{l}2-8^{\circ} \mathrm{C} \\
\mathrm{pH} 9,0\end{array}$ \\
\hline 0 & 0 & 0 & 0 & 0 & 0 & 0 \\
\hline 7 & +2 & -10 & -3 & $+3,9$ & -8 & -6 \\
\hline 14 & -8 & nd & nd & $+6,5$ & nd & nd \\
\hline 21 & +6 & nd & nd & $-6,5$ & nd & nd \\
\hline 30 & -8 & nd & nd & +6 & nd & nd \\
\hline 60 & -3 & nd & nd & $-1,4$ & nd & nd \\
\hline
\end{tabular}

$\mathrm{t}=$ tempo em dias; $\mathrm{nd}=$ não determinado 
Os parâmetros estudados na validação da metodologia, bem como a realização em laboratório com certificação NBR ISO 9001:2000, implicam temperaturas de geladeira e freezer monitoradas continuamente, manutenção preventiva dos equipamentos e, também, calibrações periódicas de pipetas e equipamentos por órgãos certificados, assegurando a qualidade do trabalho analítico e conseqüentemente a obtenção de resultados laboratoriais confiáveis.

\section{CONCLUSÃO}

De acordo com os dados obtidos conclui-se que a metodologia de CLAE desenvolvida em nosso laboratório para dosagem de porfirinas urinárias é sensível para avaliar o perfil de porfirinas eliminadas fisiologicamente pelos rins, bem como detectar alterações discretas e precoces.

\section{ABSTRACT \\ Validation of a high performance liquid chromato- graphy method for quantification of urinary porphyrins}

Porphyrins are products that originate from the heme biosyntetic pathway. Enzymes that take part in this route can have their activity inhibited due to inherited/acquired or both factors resulting in increased serum heme precursor that will be eliminated in urine. Considering the importance of early detection of heme biosynthesis alterations, the purpose of this study was to establish a high pressure liquid chromatographic (HPLC) method with fluorescence detection, to detect five fractions of porphyrins: uroporphyrin (8-carboxyporphyrin), heptaporphyrin (7carboxyporphyrin), hexaporphyrin (6-carboxyporphyrin), pentaporphyrin (5-carboxyporphyrin) and coproporphyrin I and III (4-carboxyporphyrin). Extraction methods with spectrophotometric detection are not sensitive enough for this purpose. The HPLC (Shimadzu Co., Kioto, Japan) was composed of two high-pressure pumps, auto-sampler and fluorescence detector (RF-535) with excitation at $400 \mathrm{~nm}$ and emission at $620 \mathrm{~nm}$. The sample was eluted from a reversed-phase column with a linear gradient. The linearity of the method was from 8.0 to $120 \mu \mathrm{g} / \mathrm{L}$ for all fractions, proving its ablility to identify and quantify porphyrins with differents carboxylic groups for early diagnosis and followup of porphyrias.

UNITERMS: Porphyria. Urinary porphyrins/ quantification. High performance liquid chromatography.

\section{REFERÊNCIAS BIBLIOGRÁFICAS}

ASSOCIAÇÃO BRASILEIRADE NORMAS TÉCNICAS. Sistema de gestão da qualidade: requisitos. NBR-ISO 9001. Rio de Janeiro, 2000. 21p.

BRASIL. Ministério da Saúde. Agência Nacional de Vigilância Sanitária. Medicamentos. Inspeção. Centros de Bioequivalência.Legislação. Resolução n.899, de 29 de maio de 2003. Disponível em: $<$ http://www.anvisa.gov.br/ e-legis/>. Acesso em: 20 mar. 2006.

BOZEK, P.; HUTTA, M.; HRIVNÁKOVÁ, B. Rapid analysis of poprhyrins at low $\mathrm{ng} / \mathrm{L}$ and $\mu \mathrm{g} / \mathrm{L}$ levels in human urine by a gradient liquid chromatography method uisng octadecylsilica monolithic columns. J. Chromatogr. $A$, v.1084, n.1-2, p.24-32, 2005.

CHASIN, A.; CHASIN, M.; SALVADORI, M. C. Validação de métodos cromatográficos em análises toxicológicas. Rev. Farm. Bioquím. Univ. S. Paulo, v.30, n.2, p.49-53, 1994.

DANIELL, W. E.; STOCKBRIDGE, H. L.; LABBE, R. F.; WOODS, J. S.; ANDERSON, K. E.; BISSELL, M. D.; BLOOMER, J. R.; ELLEFSON, R. D.; MOORE, R. M.; PIERACH, C. A.; SCHREIBER, W. E.; TEFFERI, A.; FRANKLIN, G. M. Chemical exposures and disturbances of heme synthesis. Environ. Health Perspect., v.105, n.1, p.37-53, 1997.

DOSS, M. O.; KÜHNEL, A.; GROSS, U. Alcohol and porphyrin metabolism. Alcohol Alcohol., v.35, n.2, p.109$125,2000$.

ELDER, G. H.; URQUHART, A. J. Biochemical indices of liver toxicity: porphyrin metabolism. In: FOÁ, V.; EMMET, E. A.; MARONI, M.; COLOMBI, A., eds. Occupational and environmental chemical hazards: cellular and biochemical indices for monitoring toxicity. Chichester: Ellis Horwood, 1987. cap.3, p.232-290.

ELDER, G.H. Porphyria cutanea tarda. Semin. Liver Dis., v.18, p.67-76, 1998.

FERNANDEZ, A. A.; HENRY, R. J.; GOLDENBERG, H. Evaluation of extraction methods and choice of instrumentation, Clin. Chem., v.12, n. p. 463-474, 1966.

FORD, R. E.; OU, C.; ELLEFSON, R. D. Liquidchromatographic analysis for urinary porphyrins. Clin. Chem., v.27, n.3, p.397-402, 1981. 
JOHNSON, P. M.; PERKINS, S. L.; KENNEDY, S. W. A high-speed liquid chromatographic method for measuring urinary porphyrins. Clin. Chem.,v.34, n.1, p.103-105, 1988.

KLAASSEN, C.D., eds. Casarett and Doull's toxicology: the basic science of poisons. 5.ed. New York: McGraw-Hill, 1996. p.159, 539.

KING, M. W.; MARCHESINI, S. Heme and porphyrin metabolism. Disponível em: $<$ http :// www .med. unibs. it/ $\sim$ marchesi/heme.html>. Acesso em: 03 jan. 2005.

LANÇONI, G. Porfiria cutânea tardia experimental: aspectos histológicos relacionados à fotossenssibilidade. Ribeirão Preto, 1999. 95p. [Dissertação de Mestrado. Faculdade de Medicina. Universidade de São Paulo].

MARTINEZ, C.A.; MILLS, G. C. Spectrophotofluorometric determination of porphyrins in urine. Clin. Chem., v.17, n.3, p. 199-205, 1971.

NATIONAL COMMITTEE FOR CLINICAL LABORATORY STANDARDS. Preparation \& testing of reagent water in the clinical laboratory. 3.ed. S.1.: NCCLS, 1997. v.17, No. 18, (NCCLS Document C3 A3).

OZALLA, D.; HERRERO, C.; RIBAS-FITÓ, N.; TOFIGUERAS, J.; TOLL, A.; SALA, M.; GRIMALT, J.; BASAGAÑA, X.; LECHA, M.; SUNYER, J.Evaluation of urinary porphyrin excretion in neonates born to mothers exposed to airborne hexachlorobenzene. Environ. Health Perspect., v.110, n.1, p.205-209, 2002.
SCHREIBER, W. E.; RAISYS, V.; LABBÉ, R. F. Liquidchromatographic profiles of urinary porphyrins. Clin. Chem., v.29, n.3, p.527-530, 1983.

SHAH, V. P.; MIDHA, K. K.; DIGHE, S.; MCGILVERAY, I. J.; SKELLY, J. P.; YACOBI, A.; LAYLOFF, T.; VISWANATHAN, C. T.; COOK, C. E.; MCDOWALL, R. D.; PITTMAN, K. A.; SPECTOR, S. Analytical methods validation: biovailability, bioequivalence and pharmacokinetic studies. Pharm. Res., v.9, n.4, p.588592, 1992.

SOBEL, C.; CANO, C.; THIERS, R. E. Separation and quantification of coproporphyrins and uroporphyrins in urine. Clin. Chem., v.20, n.11, p.1397-1402, 1974.

SUNYER, J.; HERRERO, C.; OZALLA, D.; SALA, M.; RIBAS-FITÓ, N.; GRIMALT, J.; BASAGAÑA, X. Serum organochlorines and urinary porphyrin pattern in a population highly exposed to hexachlorobenzene. Environ. Health, v.1, n.1, p.1, 2002.

VERDON, C. P.; POLLOCK, T. A.; BRALLEY, J.A. Testing for toxic metals and chemical induced porphyrinuria. Disponível em: <http://www.metametrix.com/ Publications/Toxic\%20Metals $>$. Acesso em: 21 mar. 2006.

ZUIDJDERHOUDT, F. M. J.; KOEHORST, S. G. A.; KLUITENBERG, W. E.; DORRESTEIJN-DE BOK, J. On accuracy and precision of a HPLC method for measurement of urine porphyrin concentrations. Clin. Chem. Lab. Med.,v.38, n.3, p.227-230, 2000.

Recebido para publicação em 02 de maio de 2006. Aceito para publicação em 24 de setembro de 2007. 